\title{
Acquisition and extinction as a function of magnitude and percentage of reinforcement
}

\author{
MELVIN H. MARX \\ UNIVERSITY OF MISSOURI, COLUMBIA
}

Twelve groups of six rats each were trained and extinguished on a discrete-trial barpress response under three levels of amount of reinforcement $(1,4$, and $1620-\mathrm{mg}$ food pellets) and four levels of percentage of training reinforcement $(25$, 50, 75, and 100\%). Factorial analyses of variance indicated that there was a linear relationship between acquisition scores and percentage of reinforcement, with no relative advantage for the partially reinforced groups over the 176 training trials, and that the usual runway result of greater resistance to extinction in partially reinforced groups with high amounts of reinforcement did not occur.

A number of experiments have been concerned with the relationship between magnitude of reinforcement and percentage of reinforcement as determiners of response strength in acquisition and extinction of an instrumental response (Hulse, 1958; Wagner, 1961; Wagner \& Miller, 1962). The results have indicated that acquisition is an increasing function of magnitude, with no interaction between magnitude and percentage of reinforcement; and that partially reinforced groups with a relatively large amount of reinforcement have greater resistance to extinction than partial groups with small amounts of reinforcement. Furthermore, the partial-reinforcement extinction effect was found to occur for large magnitudes but not small.

One limitation in all of these studies is the restricted range of variation: only two levels of each variable were employed. The purpose of the present experiment was to provide data on this problem from a wider range of variation in both magnitude and percentage of reinforcement, using a barpress rather than a running response, in a discrete-trial procedure. Wethot

A 3 by 4 factorial design was used. There were three levels of magnitude of reinforcement $(1,4$, and 16 20-mg Noyes food pellets) and four levels of percentage of reinforcement $(25,50,75$ and $100 \%)$.

A total of 72 naive female albino rats, purchased from the Sprague-Dawley Company and approximately 110 days old at the beginning of the experiment, were randomly distributed into the 12 experimental groups. Ten days prior to experimentation all Ss were placed on limited feeding to reduce their body weight to $85-90 \%$ of original weight.

Five days of magazine training were given in controlled-operant conditioning boxes (see Marx et al, 1965). There were 10 trials per day, with appropriate reinforcements provided every $55 \mathrm{sec}$.

Twenty-two days of barpress training were given. There were eight trials per day, with the bar presented until pressed or for a total of $55 \mathrm{sec}$ on any trial. An intertrial interval of $55 \mathrm{sec}$ was used.

Following barpress training, a massed extinction period was administered. All of the conditions were the same as in barpress training except that no reinforcement was provided in the magazine. A minimum of 80 trials and a maximum of 150 trials were used. The extinction criterion was five successive fallures to barpress.

Results

Figure 1 shows the mean barpress latencies in acquisition for the three pellet groups plotted as a function of percentage of trials reinforced. The apparent inferiority of the groups with lesser percentages of reinforcement was confirmed by an analysis of variance of the latencies, averaged over three-day blocks. The only important reliable difference was percentage of reinforcement $(F=4.08$, df $=3 / 60, p<.05)$. Neither the magnitude variable nor any of the interactions was reliable.

To test the possibility that these results were a function of early acquisition scores, a factorial analysis of variance was run over the last 18 days of training, where the curves appeared to be asymptotic. The percentage difference was still reliable $(F=4.82$, df $=3 / 60, p<.01$ ).

The mean barpress latencles in extinction were averaged in 10-trial blocks and subjected to a factorial analysis of variance. Only the trials effect and the

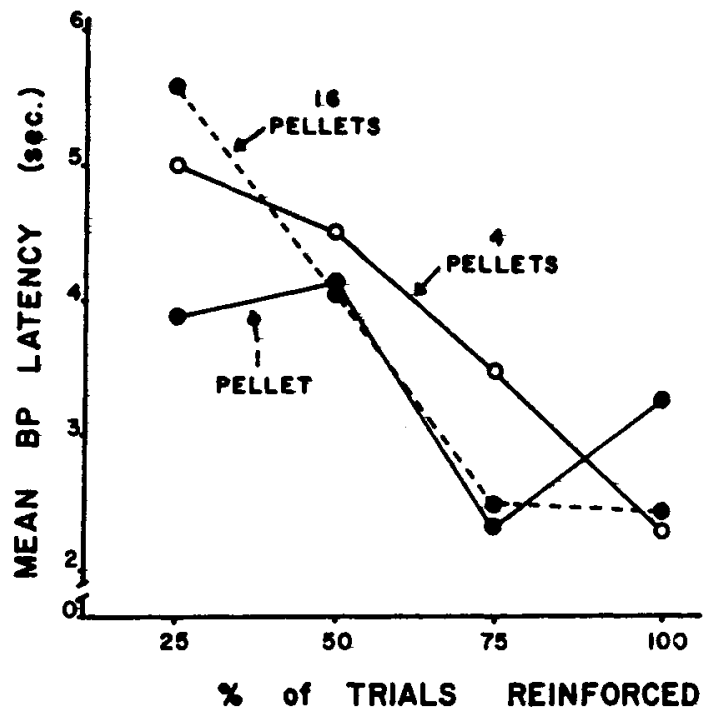

Fig. 1. Mean barpress latencies in acquisition: relationship between percentage and amount of reinforcement. 


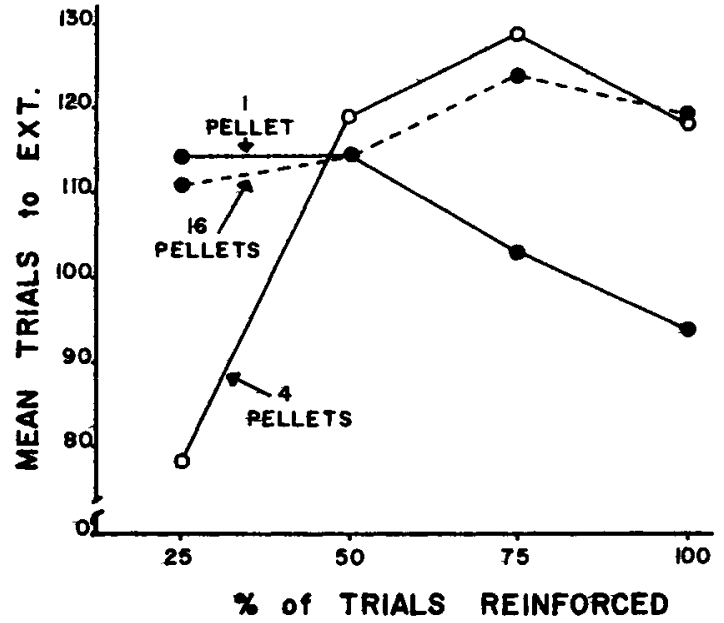

Fig. 2. Mean trials to extinction: relationship between percentage and amount of reinforcement.

trials by pellets interaction were reliable ( $F s=31.94$ and 2.08 , df $=7 / 420$ and $14 / 420, p=.01$ and .05 , respectively). The interaction reflects mainly the rapid deterioration over the last few blocks of trials of the 1-pellet group, as indicated by the fact that its terminal block mean was $17.8 \mathrm{sec}$, compared with $9.8 \mathrm{sec}$ for the 4-pellet group and $10.9 \mathrm{sec}$ for the 16-pellet group.

Additional extinction results are shown in Fig. 2, where mean trials to extinction for the three pellet groups are again plotted as a function of percentage of reinforced trials. A factorial analysis of variance performed on these data revealed a reliable pellets by percentage interaction $(F=2.05, d f=6 / 60, p<.05)$. $A$ further analysis was then performed on each of the pairs of curves; only the interaction between the 1- and 4-pellet groups was reliable $(F=4.08, \mathrm{df}=3 / 60, \mathrm{p}<.05)$, indicating a difference in trend over percentages for these two groups.

\section{Discussion}

There was obviously a rough ordering of acquisition performance as a direct function of percentage of reinforcement. These data are consistent with the results typically found for running speed in the goal box, as contrasted with the runway stem. There was no evidence for any relative improvement over trials for the partial-reinforcement groups, such as has been shown in the runway with sufficient numbers of trials and higher amounts of reinforcement. The present barpress experiment utilized a relatively great number of trials (176 over 22 days of acquisition) but relatively small amounts of reinforcement $(.02, .08$, and $.32 \mathrm{~g})$, compared with the amounts typically used in the runway (e.g., $1.0 \mathrm{~g}$ used as a maximum by Wagner, 1961, who found faster running in the partial group by the end of 60 training trials).

The extinction results plotted in Fig. 2 are somewhat more difficult to interpret. Cleariy, the results did not substantiate the typical finding in the runway of greater resistance to extinction in partial reinforcement groups with higher amounts of reinforcement. The major result of interest in this experiment is the strong suggestion of progressive deterioration in extinction performance in the lowest reinforcement group (1 pellet) as a function of increased percentage of reinforcement in training.

\section{References}

HULSE, S. H. Amount and percentage of reinforcement and duration of goal confinement in conditioning and extinction. J. exp. Psychol, 1958, 56, 1, 48-57.

MARX, M. H., TOMBAUGH, T. N., HATCH, R. S., \& TOMBAUGH, JO W. Controlled operant conditioning boxes with discrete-trial programming for multiple experiment use. Percept. mot. Skills, 1965, 21, 247-254.

WAGNER, A. R. Effects of amount and percentage of reinforcement and number of acquisition trials on conditioning and extinction. J. exp. Psychol, 1961, 62, 3, 234-242.

WAGNER, A. R., \& MILLER, N. E. Choice behavior and resistance to extinction. Psychol Rec., 1962, 12, 105-108.

Note

1. This research was supported in part by USPHS Research Grant HD 00895 from the National Institute of Child Health and Human Development and by USPHS Research Career Award 1-K6-MH-22, 023 from the National Institute of Mental Health. 